\title{
The relationships between the macroeconomic situation and European skyscrapers
}

\author{
Bartłomiej Pilch
}

\begin{abstract}
A B S T R A C T
Objective: The aim of this paper is to verify if economic prosperity is related to the number of skyscrapers built and their average height. It was done by examining the dependencies between GDP growth rate, unemployment rate, the Gini coefficient and the skyscrapers variables mentioned.

Research Design \& Methods: In order to investigate the relationship between the number of completed skyscrapers, their average height, and year, a correlation was used. Linear regression was used to verify the relationship between macroeconomic variables and those relating to skyscrapers. The macroeconomic data were obtained from the World Bank, IMF, and WTO databases, and the data referring to skyscrapers - from Emporis.com.

Findings: The time variable (year) was positively correlated with the analyzed variables linked to skyscrapers. The research showed a negative impact of the unemployment rate and a positive impact of the Gini coefficient, on the number of completed skyscrapers. Further, the economic growth was negatively and Gini coefficient values were positively related to the average height of skyscrapers.
\end{abstract}

Implications \& Recommendations: This study allows determining the periods in which an increased construction of skyscrapers could be expected. It may be useful for investors, global corporations or potential developers.

Contribution \& Value Added: The analysis provided empirical confirmation of the hypotheses about the positive correlation between the number and average height of skyscrapers and the degree of economic inequality. Also, the negative dependencies between the number of these structures and the unemployment rate and between the average height of completed skyscrapers and the GDP growth rates, based on the example of European countries, were found.

\begin{tabular}{llll}
\hline Article type: & research article & \\
$\begin{array}{l}\text { Keywords: } \\
\text { JEL codes: }\end{array}$ & skyscrapers; economic growth; GDP growth rate; unemployment rate; Gini coefficient \\
\hline \multicolumn{1}{c}{ Deceived: 13 February 2021 } & Revised: 20 March 2021 & Accepted: 22 March 2021 \\
\hline
\end{tabular}

Suggested citation:

Pilch, B. (2021). The relationships between the chosen macroeconomic data and European skyscrapers. International Entrepreneurship Review, 7(1), 33-44. https://doi.org/10.15678/ IER.2021.0701.03

\section{INTRODUCTION}

Skyscrapers, defined as multi-story buildings whose architectural height is at least 100 meters (Emporis, 2021), tend to be perceived as a symbol of wealth and power. Since their construction became commonplace, the race for the title of the world's tallest building gradually began. It was an image competition, which is most clearly presented in the 1930s - twice in 1930, and once in 1931 the record for the height of the building put into use was broken. In the case of Europe, the race for the tallest building picked up pace already in the 21st century, when the skyscraper's height record was broken 8 times (including 7 times by Russian buildings). A decisive argument in favour of the construction of high-rise buildings is decreasing space in urban areas. Therefore, it seems advisable to build higher structures, providing more office or living space (which can be clearly seen in the example of Hong Kong). However, it is also worth paying attention to the fact that the construction of skyscrapers is often associated with issues that are difficult to overcome. These include, in particular, technological barriers, legal restrictions (for example, the prohibition of the construction of this type of buildings in 
certain areas), as well as the need to adjust high-rise buildings to city centers with historic buildings, which is particularly important in Europe (Begeç \& Hamidabad, 2015) These issues limit the development of skyscrapers.

In the case of Europe, skyscrapers were not a particularly popular concept for most of the 21st century, which began to change since the 1970s. This trend is expected to continue and skyscrapers will play an important role in the architectural development of Europe (Pietrzak, 2014). Recently, a multitude of constructions of such structures has been observed, due to the growing demand for business and living spaces. It was particularly noticeable in Europe, for example in London, Moscow, Warsaw or Kyiv. Recently, the market is quite strongly affected, in a negative way, by the current pandemic situation, however, the trends pointed out above are still working - especially because of the constructions that are started before 2020. In general, skyscrapers are perceived as a sign of success and economic prosperity. However, is this belief supported by the data, based on the example of Europe? This study tries to provide an answer to this question. The aim of the article is to verify if economic prosperity is related to "the rise of skyscrapers", by estimating the relationship between the GDP growth rate, unemployment rate, Gini coefficient and the number of skyscrapers completed and their average height, based on the example of Europe.

The paper presents a brief literature review, trends in the number of skyscrapers in individual European countries and analysis using some statistical tools (like correlation and regression). In the empirical part of the paper, the data related to the number and the average height of the skyscraper built were compared with economic growth rates, unemployment rates and the Gini coefficient.

\section{LITERATURE REVIEW}

\section{Skyscrapers: symbols and happiness}

The figures of skyscrapers are easily seen as symbols, which gives some room for maneuver to companies that want to be seen as synonyms of success and development, not just economic growth. It is easier to create a symbolic value in the form of a skyscraper than to improve general well-being. Likewise, skyscrapers are usually associated with corporations as their symbols. Typically, objects like shopping malls, culture centres or theme parks are not as clearly associated with corporations like skyscrapers (Sklair, 2006). On the other hand, high-rise buildings also have tangible advantages, which are also beneficial for the environment - examples are energy efficiency and environmental friendliness (Michaelson, 2014). A kind of excuse for the construction of taller and taller skyscrapers is the idea of "green skyscraper", which on the one hand can be considered a marketing gimmick, but on the other - as an example of actually beneficial - for the environment, and even for the economy, action (McNeill, 2005). Apart from the benefits connected with the environment, the construction of skyscrapers has a positive impact on some countries, for instance emerging markets, in some ways. That is, especially, attracting foreign investors, which, due to the scarcity of natural resources (e.g. the shrinking oil deposits in the Middle East), seems to be a fairly good source of stimulating investments in the economy, or the creation of financial districts where many transnational corporations outsource, creating new jobs (Formaneck, 2013). The role of skyscrapers in cities seems to be more and more important. With the influx of people to urban areas, there is gradually a shortage of building space. Therefore, three possible ways of developing skyscrapers are referenced - horizontal overcrowding, urban sprawl and vertical expansion. It seems necessary not to destroy agricultural lands during the cities' development processes, and that is the way focused on skyscrapers (Al-Kodmany, 2018). It is also noted that skyscrapers are not only symbols of power and hierarchy, but also examples of being guided by the organization of the capital accumulation process. On the other hand, they are also often seen as a sign of social inequality (Barr, 2016). Overall, however, they should be perceived as examples of a good organization (Parker, 2013). Skyscrapers might have also a correlation with happiness. According to Barr and Johnson (2020), building high-rises has no significant impact on the level of happiness. However, for skyscrapers, there was found a positive influence of these types of constructions on society happiness. The research showed also that there is no negative influence of skyscrapers on the overall health of society. Similarly, an empirical study of the relationship between skyscraper 
height and happiness showed a positive one. Depending on the regression method adopted, it was either insignificant or statistically significant (Barr, 2017).

In general, skyscrapers are seen as an image of proper management in the economic sphere and socio-economic development of the country. It is also worth focusing on the relationships between the eponymous structures and quite measurable economic concepts, such as business cycles.

\section{Skyscrapers and business cycles}

One of the most famous connections between skyscrapers and business cycles is the Skyscraper Curse (or the Skyscraper Effect/the Skyscraper Index), described by Lawrence (1999). The author stated that economic crises were often preceded by breaking the world height record by a skyscraper. However, he also pointed out the exception of this conception - after the Woolworth Building was put into use in 1913, there was no immediate crisis in the next few years. In general, this conclusion was based on the reasoning that investment in skyscrapers increases throughout a period of cyclical economic growth until it enters a recessionary phase (Thornton, 2005). Kaza (2010) presented a slightly different, more regional approach to this issue. He analyzed the 20 tallest buildings in chosen US states, concluding, however, that the Skyscraper Effect "is not meant to be a predictor of either economic contraction or financial crisis". Another analysis was also conducted on the example of Great Britain. Jadevicius (2016) stated that there is a positive correlation between the announcement of the tallest building in UK and a business cycle peak. He also drew attention to the reasons confirming this dependence: low interest rates, easy to obtain a loan, employing a larger number of employees, increasing demand for office and residential space contribute to greater activity in the construction sector, where the skyscrapers are particularly attractive due to the decreasing number of vacant building space in cities. Also, a study conducted on the example of the Korean market showed a relationship between the construction of skyscrapers and the economy of the region. The differentiation of gross area (a variable related to skyscrapers) turned out to have a temporary negative impact on the Gross Regional Domestic Product, which is consistent with the previously mentioned conclusions (Heo et al., 2013). Further, Thornton (2005) took especially the Woolworth Building into account, as a counterexample of the Skyscraper Index idea. Despite the common belief that there was no crisis in the period immediately after 1913, he noted that in the years 1913-1914 there was a significant economic slowdown, which, however, is often not noticed due to the outbreak of World War I. This period could therefore confirm the idea of the Skyscraper Effect. What is more, he also suggests a possible interpretation of the issue taken into account - skyscrapers reaching record heights and severe business cycles are related to the instability in debt financing. Hence, institutions that are involved in regulating it, ought to be improved or replaced. What is more, it is also worth paying attention to the reasons for possible differences in the assessment of the effectiveness of the Skyscraper Effect. These include divergent analysis methods, different criteria and different time series. The ideological differences related to the recognition of the causes and effects of business cycles in the economy cannot be overlooked. Therefore, the discussion on the Skyscraper Index might be perceived as an analogy of the dialogue between various ideological trends in economics (Kachniarz, 2014). It is also worth mentioning, that there is a correlation between skyscraper construction and investors' sentiment and market credit terms. Over-optimism might lead to the intensification of skyscraper construction and overvalue in stock markets, which may direct towards the economic slump. These findings are quite consistent with the previously mentioned ones (Löffler, 2013). The test of the relationship between the height of skyscrapers and output was carried out in 2011 referring to the beliefs that the authors believed were common:

1. the presence of the sharpest growth of height competition near the peak of the business cycle,

2. extreme skyscrapers as an example of irrational actions of investors.

A study using the Granger causality test indicated that production influences the "height" variable. These variables are correlated, albeit to a small extent, although it can be considered as a certain, partial confirmation of the theses put forward by the authors cited earlier (Barr et al., 2011).

In general, the connection of high-rise buildings with the macroeconomic situation can be explained as follows: the economic up-turn affects the increase in demand for real estate, which leads, 
among others, to increase rents. As a result, a "building boom" can be observed, which increases with economic growth (Barras, 1994). Then more buildings are built, also of greater height - this is especially true for skyscrapers. It is claimed that "economic fundamentals are a key driver of skyscraper construction" (Barr \& Luo, 2020). This shows, for example, potential links with the number and height of skyscrapers built: positive for economic growth, negative for the unemployment rate. Through the prism of the gradually improving general economic situation, as well as improvements in construction technology, this also applies to the hypothesis about the construction of an increasing number of higher and higher buildings in the following years. Further, in the case of developed economies, which include many European ones, economic growth may result in an decrease in economic inequalities (Kuznets, 1955). Hence, one can potentially expect a negative correlation of these inequalities (measured by the Gini coefficient) with the variables relating to skyscrapers - their number and height.

\section{RESEARCH METHODOLOGY}

As noted, studies focusing on the relationship between skyscrapers and macroeconomic values usually refer to the concept of the Skyscraper Index. However, there are almost no studies taking into account the correlation between skyscraper measures and economic development. Therefore, in the empirical part of the study, it was decided to analyze the relationship between the economic growth rate, unemployment rate (as the most popular macroeconomic variables relating to the real sphere) and the number and average height of completed skyscrapers, which might be considered as the aim of this paper. A measure relating to social inequalities - the Gini coefficient - was also taken into account. The analysis was carried out on the basis of European countries, covering the period 1961-2020. However, usually, the study period turned out to be shorter due to the lack of some data, e.g. for Russia before 1990. Buildings of the office and residential type were considered skyscrapers, the height of which is not less than $100 \mathrm{~m}$. What is more, in the sample there are also buildings, which are topped out (according to the methodology of Emporis (2021), from where the data was obtained).

Research hypotheses were formulated based on common beliefs and a literature review. Their content is consistent with the purpose of the study presented above. They are as follows - on the example of European countries:

H1a: There is a significant positive relationship between the number of built skyscrapers and a year of their completion

H1b: There is a significant positive relationship between the height of skyscrapers and a year of their completion.

H2a: There is a significant positive relationship between GDP growth rate and the number of completed skyscrapers,

H2b: There is a significant positive relationship between GDP growth rate and the height of skyscrapers.

H3a: There is a significant negative relationship between the unemployment rate and the number of completed skyscrapers.

H3b: There is a significant negative relationship between the unemployment rate and the height of skyscrapers.

H4a: There is a significant negative relationship between the Gini coefficient and the number of completed skyscrapers.

H4b: There is a significant negative relationship between the Gini coefficient and the height of skyscrapers.

Macroeconomic data (GDP growth rates, unemployment rates, Gini coefficient values) were obtained from the World Bank, International Monetary Fund and World Health Organization databases. The analysis was carried out separately for countries with the largest number of skyscrapers in Europe and for the entire sample (European countries with skyscrapers). Correlation and regression were used to estimate the relationships presented in the hypotheses. The equations of linear regression used in this study are as follows: 
where:

$$
\begin{aligned}
& n_{t}=\beta_{1} * d G D P_{t-2}+\beta_{2} * G I N I_{t-2}+\beta_{3} * U N E_{t-2}+\varepsilon_{t} \\
& H_{t}=\beta_{1} * d G D P_{t-2}+\beta_{2} * G I N I_{t-2}+\beta_{3} * U N E_{t-2}+\varepsilon_{t}
\end{aligned}
$$

$n$ - the number of skyscrapers built in a given year;

$d G D P$ - GDP growth rate;

GINI - Gini coefficient;

$U N E$ - unemployment rate;

$H$ - mean height of skyscrapers built in a given year.

It is worth noting that the construction of skyscrapers in European conditions usually takes about $2-2,5$ years. Hence, the variables relating to the height of skyscrapers and the number of such structures for the year were delayed by 2 years. Apart from it, there is no problem of collinearity between the explanatory variables, which allows them to be used together in a linear regression model. It was decided to use the OLS method because this analysis can be considered as a signal of the research potential of the area of links between skyscrapers, their number and average height, and macroeconomic variables. As part of further research, it is worth considering using models based on panel data.

\section{RESULTS AND DISCUSSION}

\section{Situation and tendencies related to the European skyscrapers}

Before measuring the relationship between the above-mentioned measures, it is also worth taking the trends observed on the European skyscraper market into account. In the beginning, the brief focus was on the tendencies in the construction of skyscrapers observed in European countries over the past years. Attention was drawn to the number of skyscrapers completed in the years 19612021, as shown in Figure 1.

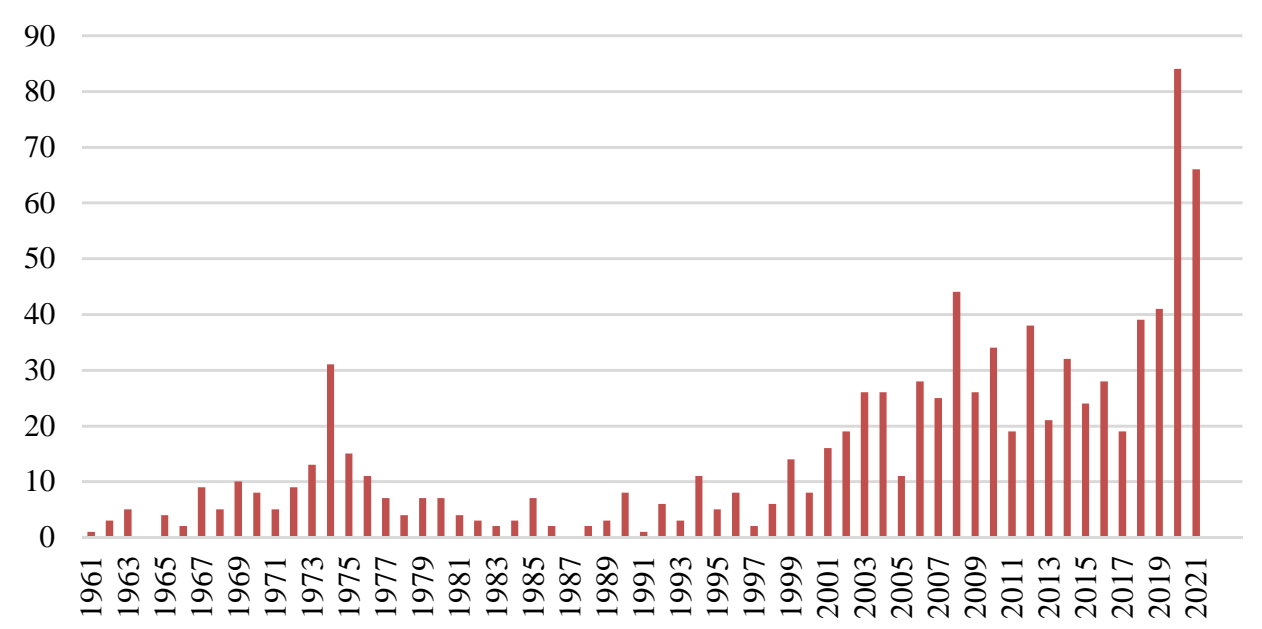

Figure 1. The number of completed skyscrapers in a given year in Europe in the period 1961-2021 Source: author's own work based on Emporis (2021).

As stated earlier, the last decade has been full of skyscraper construction in Europe. The year 1974, which stands out from the 1960s, 1970s, 1980s and 1990s, is noteworthy. This year, 31 skyscrapers were built, 20 of which were in France. In general, it seems that more and more skyscrapers have emerged in recent years. This view is empirically confirmed - especially in the 21st century, a growing trend in their numbers from year to year was observed. The correlation between the year of construction and the number of skyscrapers was relatively high, at the level of 0.673 . For comparison, in the 21st century, 675 skyscrapers have been built in Europe so far, while in the years 1961-2000 - only 
254. This shows that the scale of construction of the title buildings has increased noticeably in recent years. One may wonder to what extent these changes are driven by economic growth.

Next, attention was paid to the number of skyscrapers built in individual European countries. The number of these buildings by country is presented in Table 1.

Table 1. Number of skyscrapers by European country in 2021

\begin{tabular}{|l|c|l|c|l|c|}
\hline \multicolumn{1}{|c|}{ Country } & No. & \multicolumn{1}{c|}{ Country } & No. & \multicolumn{1}{c|}{ Country } & No. \\
\hline Albania & 1 & France & 95 & Poland & 35 \\
\hline Austria & 16 & Germany & 83 & Portugal & 4 \\
\hline Belarus & 4 & Greece & 1 & Romania & 5 \\
\hline Belgium & 20 & Italy & 37 & Russia & 275 \\
\hline Bosnia and Herzegovina & 4 & Latvia & 5 & Serbia & 5 \\
\hline Bulgaria & 4 & Lithuania & 2 & llovak Republic & 13 \\
\hline Croatia & 4 & Luxembourg & 4 & Spain & 76 \\
\hline Cyprus & 5 & Macedonia & 4 & Sweden & 9 \\
\hline Czech Republic & 4 & Montenegro & 5 & Switzerland & 6 \\
\hline Denmark & 5 & Netherlands & 49 & Ukraine & 38 \\
\hline Estonia & 4 & Norway & 2 & United Kingdom & 133 \\
\hline Finland & 2 & \multicolumn{2}{|}{} \\
\cline { 1 - 4 }
\end{tabular}

Note: No. - the number of skyscrapers built in a given country.

Source: author's own work based on Emporis (2021).

The European countries where most of the continent's skyscrapers were built are Russia, the United Kingdom, France, Germany and Spain. These countries are usually seen as the economic powers of Europe, which would be consistent with the hypothesis of a positive relationship between the strength of the economy and the number of skyscrapers constructed. On the other hand, relatively few skyscrapers were built in Scandinavia, despite the high degree of economic development of countries such as Norway, Sweden and Finland. In recent years, a relatively large number of skyscrapers have also been built in Poland (especially in Warsaw), Ukraine (mainly in Kiev) and Italy.

It is also worth paying attention to the relationship between the height of skyscrapers and the year of their completion. It seems, also in line with hypothesis 1, that one can expect a positive correlation between these variables. Figure 2 shows this relationship.

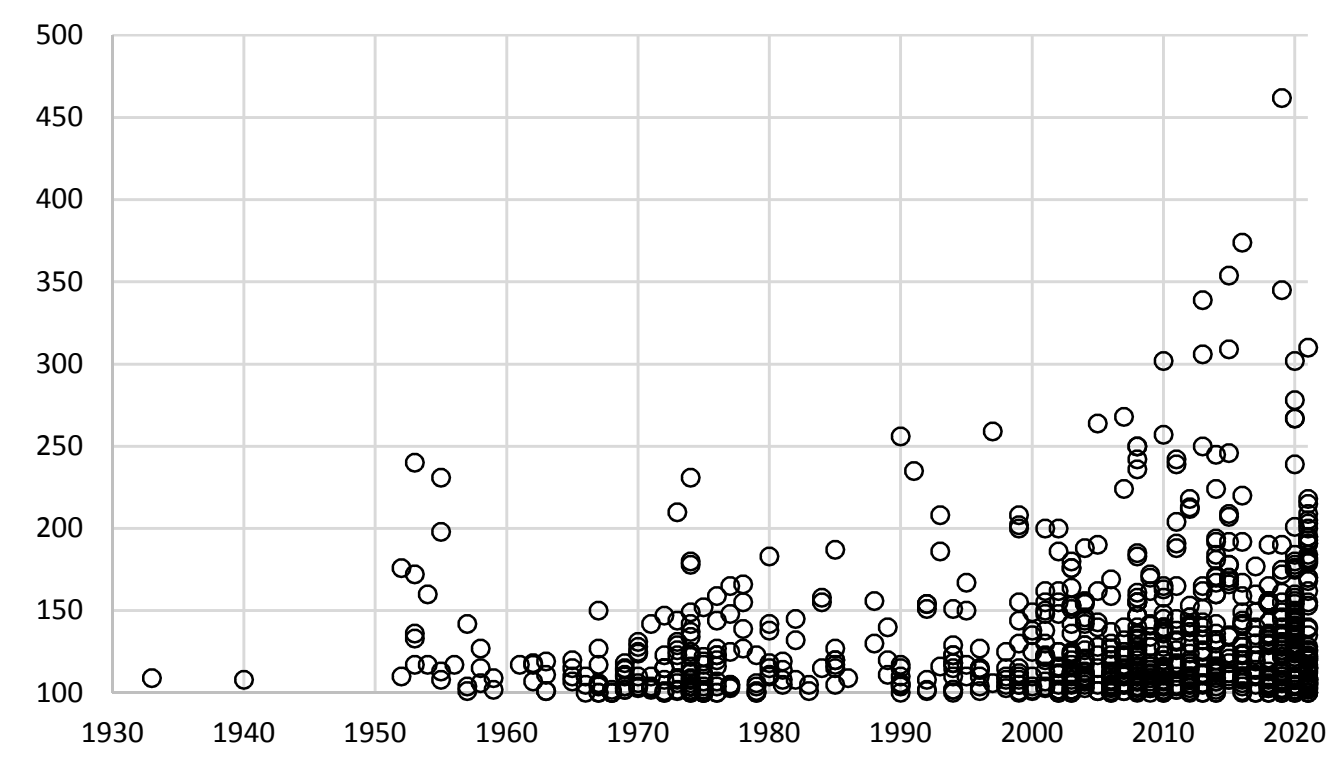

Figure 2. The relationship between the height and the year of completion of European skyscrapers in the period 1930-2021

Source: author's own work based on Emporis (2021). 
As it can be seen, the vast majority of skyscrapers reach a height of between 100 and $150 \mathrm{~m}$. The largest number of such structures was built in the 1970s and since 2000. The intensified race for the title of the tallest building in Europe or the European Union began to be observed relatively recently, all European skyscrapers over $300 \mathrm{~m}$ were built in the 21st century. In general, there is a statistically significant correlation between the height of the skyscraper and the year of its completion, although the level of correlation between these variables is small (0.171). This result, however, is in line with the common belief in building taller and taller buildings. Therefore, in this context, taking also into account the conclusions based on Figure 1 , hypothesis 1 can be considered as a confirmed one. The decreasing free space in city centers or the willingness to settle in urban areas, based on the example of Europe, have in recent years contributed to the intensification of the construction of skyscrapers, characterized by the increasing height of these structures.

\section{Empirical analysis of the relationships between macroeconomic data and European skyscrapers}

The next empirical part of this paper is focused on the number of skyscrapers built in a given year and their average heights. Initially, the focus was on the correlation between the GDP growth rate, unemployment rate, Gini coefficient values and variables referred to the skyscrapers. The calculation results of these measures are presented in Table 2.

Table 2. Correlation between macroeconomic indicators and the skyscraper variables in given European countries in the period 1961-2020

\begin{tabular}{|l|c|c|c|c|c|c|}
\hline \multicolumn{1}{|c|}{ Country } & H-dGDP & n-dGDP & H-UNE & n-UNE & H-GINI & n-GINI \\
\hline France & $-0.461^{* * *}$ & $0.349 * * *$ & 0.266 & $-0.494^{* * *}$ & -0.099 & 0.273 \\
\hline Germany & 0.068 & -0.047 & -0.224 & 0.176 & 0.037 & -0.264 \\
\hline Italy & -0.178 & -0.418 & 0.135 & 0.180 & 0.447 & 0.119 \\
\hline The Netherlands & -0.496 & $-0.165^{* *}$ & 0.069 & $-0.432^{* * *}$ & -0.412 & -0.214 \\
\hline Poland & -0.355 & 0.168 & -0.249 & -0.243 & -0.292 & -0.160 \\
\hline Russian Federation & -0.009 & 0.293 & $-0.414^{* *}$ & $-0.548^{* * *}$ & 0.237 & -0.152 \\
\hline Spain & 0.128 & -0.165 & -0.007 & -0.133 & -0.123 & -0.267 \\
\hline Ukraine & 0.265 & 0.107 & 0.200 & -0.356 & 0.155 & -0.330 \\
\hline United Kingdom & -0.061 & -0.152 & 0.262 & $-0.421^{* * *}$ & -0.266 & -0.101 \\
\hline
\end{tabular}

$* ; * * ; * *$ means in sequence: statistically significant at the level of $0.01 ; 0.05 ; 0.10$.

Source: author's own work based on Emporis (2021).

The results presented above are somewhat differentiated. On the example of France, along with the ever-higher rates of GDP growth, the average height of the constructed skyscrapers decreased. On the other hand, the number of completed skyscrapers showed a positive correlation with GDP growth. This means that the favorable economic situation is reflected in the growing number of completed skyscrapers, although their average height then decreases. The same signs of estimation are observed in the case of Poland and Russia, however, they are statistically insignificant. In the case of the Netherlands, there was a negative correlation between GDP growth rate and skyscraper variables (height or number). This indicates the negative impact of economic growth on the number and average height of the constructed skyscrapers, which is rather contrary to the assumed hypotheses. Likewise, such directions of dependence were also observed for Italy and the United Kingdom (but they are also not statistically significant).

In most cases, unemployment was negatively related to the number of skyscrapers constructed. This conclusion is in line with the expectations and hypothesis 3 . This relationship with the greatest strength is observed for Russian Federation, France, the Netherlands and the United Kingdom. However, there are other types of observable relationships between unemployment and the average height of skyscrapers, where only in the case of Russia such a relationship can be considered significantly negative. As the unemployment rate rises, fewer high-rise buildings can be expected. As for their height - it is impossible to clearly define its average sign for this sample, there is a significant differentiation in this case.

On the example of the analyzed sample, no statistically significant relationships were found between the number of skyscrapers completed in a given year or their average height and the Gini coefficient. Especially in this case, however, one cannot ignore the fact that relatively few observations of the Gini 
coefficient are available, hence the correlations at an absolute level exceeding 0.4 are still statistically insignificant. However, taking into account the estimates of most of the coefficients, with access to more data, it could be expected that there are negative correlations between the number of skyscrapers and the Gini coefficient on average. This conclusion can be considered in line with hypothesis 4 , according to which the construction of high-rise buildings is associated with decreasing socio-economic inequalities.

Overall, the interpretation of statistically significant rates was as expected for Russia, 2 out of 3 for France, 1 out of 2 for the Netherlands, and 1 for the United Kingdom (thus $75 \%$ of the rates). On the basis of these observations, it could be concluded that the increase in the unemployment rate negatively influenced the number of skyscrapers, which partially confirms hypothesis 3 . In the case of the analysis of relationships between the variables n-dGDP, H-dGDP, H-UNE and n-GINI, the results differed significantly between countries. The " $n$ " variable seems to be negatively related to the Gini coefficient on the example of the 9 analyzed countries, which would indicate a linear relationship between the decrease in socio-economic inequalities and the number of skyscrapers constructed, however, these dependencies are statistically insignificant. On the other hand, it is worth bearing in mind that the statistical insignificance of most estimates does not result from the lack of a linear relationship between the variables, but rather from the small amount of available data (e.g. in the case of the Gini coefficient or the number of completed skyscrapers in some of the analyzed countries). The correlations between individual variables vary significantly between countries, due to the already mentioned low (and different between countries) data availability or a different period of analysis.

Hence, the relationships were examined taking into account the average for Europe (variables $n$ and $\mathrm{H}$, as well as macroeconomic variables relating to the entire continent). The estimates of the parameters of the models with the sum of constructed skyscrapers as a dependent variable are shown in table 3.

Table 3. Models with $\mathrm{n}$ as a dependent variable, estimated on the basis of European data in the period 1961-2020

\begin{tabular}{|l|l|c|c|}
\hline \multicolumn{2}{|c|}{ Parameter/feature } & Model 1 & Model 2 \\
\hline \multirow{4}{*}{ dGDP } & Coefficient & 0.5583 & - \\
\cline { 2 - 4 } & Std. error & 0.4077 & - \\
\cline { 2 - 4 } & P-value & 0.1981 & 1.3233 \\
\hline \multirow{4}{*}{ GINI } & Coefficient & 1.2193 & 0.2187 \\
\cline { 2 - 4 } & Std. error & 0.2219 & $5.75 \mathrm{e}-05$ \\
\cline { 2 - 4 } & P-value & 0.0002 & -1.7150 \\
\hline \multirow{3}{*}{ UNE } & Coefficient & -1.4430 & 0.8022 \\
\cline { 2 - 4 } & Std. error & 0.7905 & 0.0538 \\
\cline { 2 - 4 } & P-value & 0.0952 & 0.6627 \\
\hline$R^{2}$ & & 0.7124 & 0.6346 \\
\hline Adjusted R & 0.6601 & 830.6572 \\
\hline F test value & 607.9978 & $1.36 \mathrm{e}-13$ \\
\hline P-value for F test & $1.69 \mathrm{e}-12$ & \\
\hline
\end{tabular}

Source: author's own work based on Emporis (2021) using GRETL.

Referring to the estimation of the UNE parameter, it can be concluded that the negative correlation observed between unemployment and the number of skyscrapers in only a few countries is reflected in the entire sample of European countries. The estimation of the GINI parameter is also statistically significant, but its value was positive. Other conclusions could be drawn initially on the example of selected European countries, however, the regression results indicate that socio-economic inequalities are deepening along with the increase in the number of skyscrapers constructed. On the other hand, GDP growth seems to be positively related to the " $n$ " variable - periods of better economic conditions abounded in high-rise construction, however, it cannot be conclusively stated on the basis of the above model. As a part of backward stepwise regression, the variable with the highest $p$-value was removed from the model, it was dGDP. The model without this variable was characterized by a lower degree of fit to the data, however, the estimates of other parameters remained similar. In general, on the basis of the above models, it can be concluded that the unemployment rate is negatively related and the 
Gini coefficient is positively related to the number of skyscrapers. Hence, hypothesis $3 a$ can be considered confirmed, whereas hypothesis $4 a-$ rejected.

The further part of the study focuses on the relationship between the average height of skyscrapers and macroeconomic variables. Models built to estimate these dependencies are presented below.

Table 4. Models with $\mathrm{H}$ as a dependent variable, estimated on the basis of European data in the period 1961-2020

\begin{tabular}{|l|l|c|c|}
\hline \multicolumn{2}{|c|}{ Parameter/feature } & Model 3 & Model 4 \\
\hline \multirow{4}{*}{ dGDP } & Coefficient & -2.6026 & -3.0032 \\
\cline { 2 - 4 } & Std. error & 1.4397 & 1.4897 \\
\cline { 2 - 4 } & P-value & 0.0980 & 0.0668 \\
\hline \multirow{4}{*}{ GINI } & Coefficient & 2.8738 & 4.2350 \\
\cline { 2 - 4 } & Std. error & 0.8917 & 0.1329 \\
\cline { 2 - 4 } & P-value & 0.0081 & $5.75 e-013$ \\
\hline \multirow{4}{*}{ UNE } & Coefficient & 4.9292 & - \\
\cline { 2 - 4 } & Std. error & 3.1842 & - \\
\cline { 2 - 4 } & P-value & 0.1499 & - \\
\hline$R^{2}$ & & 0.3415 & 0.2306 \\
\hline Adjusted R & 0.2218 & 0.1665 \\
\hline F test value & & 796.0552 & 758.8241 \\
\hline P-value for F test & $3.86 \mathrm{e}-13$ & $2.33 \mathrm{e}-13$ \\
\hline
\end{tabular}

Source: author's own work based on Emporis (2021) using GRETL.

The parameter estimate for the dGDP variable is below 0 . This indicates a negative correlation between GDP growth rates and the average height of European skyscrapers completed in a given year. This is a different result than expected. On the other hand, the relationship between the Gini coefficient and the dependent variable is positive, as in the case of 1-2 models. There was no statistically significant correlation between the unemployment rate and the average height of the constructed skyscrapers, however, the estimation of the parameter with the UNE variable allows to suppose that these variables are positively related. Taking everything into account, it can be concluded that the degree of socio-economic inequality, measured by the Gini coefficient, is positively related to the average height of the constructed skyscrapers, which allows accepting hypothesis $4 \mathrm{~b}$ as false. GDP growth turned out to be negatively related to the variable $\mathrm{H}$. Hypothesis $2 \mathrm{~b}$ should also therefore be rejected. The models presented above do not fit the data very well (although the 1-2 models could be considered acceptable in this regard). However, through the prism of this study, it seems that the relationships between the explanatory variables and the number of constructed skyscrapers and their average height are more crucial.

\section{CONCLUSIONS}

This study provides some empirical insight into how macroeconomic variables are related to the number of skyscrapers built and their height. Overall, the number of skyscrapers constructed and their average height turned out to be positively related to the time variable (years). This means that, on the example of Europe, in the period 1961-2020, each year on average more skyscrapers of higher height were built. This is in line with the results of the study by Ahlfeldt and Barr (2020).

The relationships between the GDP growth rate, unemployment rate, Gini coefficient and the number and average height of skyscrapers constructed in Europe were different between the analyzed 9 countries. In the case of the entire sample (where more observations could be distinguished, which makes it more reliable), a positive correlation between the Gini coefficient, and a negative relationship between the unemployment rate and the number of skyscrapers constructed were observed, which can be considered consistent with the popular views. However, the conclusion regarding the Gini coefficient is inconsistent with the hypothesis based on the theory of Kuznets (1955). The average height of skyscrapers turned out to be negatively related to the GDP growth rates, and positively related to the Gini coefficient. In times of economic prosperity, when the unemployment rate is lower, more skyscrapers 
were built. However, higher economic growth affects the construction of lower average skyscrapers. Also, the more socio-economic inequalities deepened, the number of completed skyscrapers, and its average height is higher. The negative correlation between the average height of skyscrapers and the GDP growth can be considered consistent with the result of the study by Heo et al. (2013). Further, according to Löffler (2013), economic over-optimism, for instance, related to the drop in the unemployment rate, may intensify the construction of skyscrapers. This statement is in line with the negative relationship between the unemployment rate and the number of completed skyscrapers. The positive relationship between the Gini coefficient and the skyscraper variables is consistent with the work of Barr (2016). As indicated, this paper can be treated as a preliminary attempt to confirm theses regarding the connection between economic growth or economic inequalities and the construction of skyscrapers.

This study allows determining the periods in which an increased construction of high-rise buildings could be expected. It may be useful from the point of view of investors interested in the office space market in high-rise buildings, global corporations looking for appropriate buildings for their offshore headquarters or for potential developers of this type of housing investments.

It is worth bearing in mind that the relationships observed on the basis of data from 1961-2020 do not necessarily repeat in the future. The most significant research limitations include also the relatively low availability of observations for the Gini coefficient, which could have influenced the results of the analysis. In addition, some of the countries considered are characterized by a relatively low number of skyscrapers (especially completed in the periods 1960-1970 and 1980-1990), which is also not insignificant.

Among suggestions for further research, it could be mentioned taking other countries (for instance from Asia or North America) into account and also an extension of the analysis period. This may make particular sense in the case of the analysis of skyscrapers in the United States, where the history of such buildings is by far the longest. In the case of research based on several countries, it is worth considering panel models.

\section{REFERENCES}

Ahlfeldt, G. M., \& Barr, J. M. (2020). The Economics of Skyscrapers: A Synthesis. Centre for Economic Performance Discussion Paper, 1704.

Al-Kodmany, K. (2018). Skyscrapers in the Twenty First Century City: A Global Snapshot. Buildings, 8(12). https://doi.org/10.3390/buildings8120175.

Barr, J. M. (2016). Building the Skyline: The Birth and Growth of Manhattan's Skyscrapers. Oxford University Press.

Barr, J. M. (2017). Regression Results for Skyscraper and Height Happiness. Retrieved February, 28 from https://buildingtheskyline.org/wp-content/uploads/2017/12/Blog-6-Data-and-Regressions.pdf.

Barr, J. M., \& Johnson, J. (2020). Skyscrapers and the Happiness of Cities. Eastern Economic Journal, 46 (8), 344377. https://doi.org/10.1057/s41302-019-00163-2.

Barr, J. M., \& Luo, J. (2020). Growing Skylines: The Economic Determinants of Skyscrapers in China. The Journal of Real Estate Finance and Economics, https://doi.org/10.1007/s11146-020-09764-7.

Barr, J. M., Mizrach, B., \& Mundra, K. (2011). Skyscraper Height and the Business Cycle: International Time Series Evidence. Rutgers University Newark Working Paper, \#2011-003.

Barras, R. (1994). Property and the Economic Cycle: Building Cycles Revisited. Journal of Property Research, 11(3), 183-197. https://doi.org/10.1080/09599919408724116.

Begeç, H., \& Hamidabad, D. S. (2015). Is There a Limit for the Skyscrapers?. 9th International Sinan Symposium, Edirne. 9.

Emporis (2021). Europe. Retrieved from https://www.emporis.com/ on February 28, 2021.

Formaneck, S. D. (2013). Skyscrapers and Economic Strategy of Development: The Case of Bahrain's Proposed Murjan Tower. Journal of Economics, Business and Management. 1(4), 350-354. https://doi.org/10.7763/JOEBM.2013.V1.76.

Heo, J.-Y., Kim, H.-J., \& Jung, Ch.-M. (2013). Effects on Business Cycles by Constructing Skyscrapers in Seoul. Journal of the Architectural Institute of Korea Planning \& Design, 29(6), 213-221. 
World Health Organization (2020). Indicators - the Gini coefficient. Retrieved from https://gateway.euro.who.int/en/indicators/hfa_617-0280-gini-coefficient-income-distribution on February 28, 2021.

Jadevicius, A. (2016). Skyscraper Indicator and its Application in the UK. Entrepreneurial Business and Economic Review, 4(2), 37-49. https://doi.org/10.15678/EBER.2016.040204.

Kachniarz, M. (2014). "Skyscraper index" - czy wieżowce wieszczą krach?. Zeszyty Naukowe Uniwersytetu Szczecińskiego, Studia i Prace Wydziału Nauk Ekonomicznych I Zarzqdzania, 37(3), 21-31.

Kaza, G. (2010). Note: Wolverines, Razorbacks and Skyscrapers. The Quarterly Journal of Austrian Economics, 13(4), 74-79.

Kuznets, S. (1955). Economic Growth and Income Inequality. The American Economic Review, 45(1),1-28.

Lawrence, A. (1999). The Skyscraper Index: Faulty Towers. Property Report. Dresdner Kleinwort Waserstein Research.

Löffler, G. (2013). Tower Buildings and Stock Market Returns. Journal of Financial Research, 36(3), 413-434. https://doi.org/10.2139/ssrn.1787517.

McNeill, D. (2005). Skyscraper geography. Progress in Human Geography, 29(1), 41-55. https://doi.org/10.1191/0309132505ph527oa.

Michaelson, Ch. (2014). The Competition for the Tallest Skyscraper: Implications for Global Ethics and Economics. CTBUH Research Papers, IV, 20-27.

Parker, M. (2013). Vertical capitalism: Skyscrapers and organization. Culture and Organization, 21(3), 1-18. https://doi.org/10.1080/14759551.2013.845566.

Pietrzak, J. (2014). Development of high-rise buildings in Europe in the 20th and 21st centuries. Challenges of Modern Technology, 5(4), 31-38.

Sklair, L. (2006). Iconic architecture and capitalist globalisation. City, 10(1), 21-47. https://doi.org/10.1080/13604810600594613.

Thornton, M. (2005). Skyscrapers and business cycles. The Quarterly Journal of Austrian Economics, 8(1), 51-74. https://doi.org/10.1007/s12113-005-1016-3.

The World Bank (2020). World Development Indicators. Retrieved February, 28 from https://databank.worldbank.org/source/world-development-indicators\#.

The International Monetary Fund (2020). World Economic Outlook. The International Monetary Fund database. Retrieved February, 28 from https://www.imf.org/external/datamapper/datasets/WEO. 


\section{Author}

\section{Bartłomiej Pilch}

Bachelor in Economics and Finance. Currently Master Student of Economics and Finance at Cracow University of Economics (Poland).

Correspondence to: Bartłomiej Pilch, Poland, e-mail: bpilch98@gmail.com

ORCID (1) http://orcid.org/0000-0002-0081-4050

\section{Acknowledgements and Financial Disclosure}

The author would like to thank the anonymous referees for their useful comments, which allowed to increase the value of this article.

\section{Conflict of Interest}

The authors declare that the research was conducted in the absence of any commercial or financial relationships that could be construed as a potential conflict of interest.

\section{Copyright and License}

This article is published under the terms of the Creative Commons Attribution - NoDerivs (CC BY-ND 4.0) License http://creativecommons.org/licenses/by-nd/4.0/ 